\title{
FRONTEIRA E INTEGRAÇÃO TERRITORIAL NA ESCRITA DA HISTÓRIA "DIDÁTICA" OITOCENTISTA
}

\author{
Luís César Castrillon Mendes* \\ Renilson Rosa Ribeiro**
}

\begin{abstract}
RESUMO: Durante o período regencial, em 1838, entravam em funcionamento duas instituições que objetivavam criar e legitimar escritas históricas para forjar uma nação para o recém-emancipado Estado brasileiro: o Instituto Histórico e Geográfico Brasileiro (IHGB) e o primeiro Colégio em que a História se tornaria disciplina escolar. Para atingir os objetivos de consolidação da nação, a integração territorial e a delimitação de suas fronteiras tornavam-se fundamentais. Objetiva-se, no presente texto, analisar o IHGB e o Colégio Pedro II, enquanto entidades ligadas ao Estado imperial, organizadoras de um projeto de construção nacional em que se fazia necessária a ratificação de suas fronteiras, buscando legitimações discursivas, fundamentadas nas explorações do território realizadas em séculos anteriores, nas quais o desenho do território, resultado histórico da política expansionista lusitana, constituiu-se em uma espécie de tradição.

PALAVRAS-CHAVE: Fronteira; Território; IHGB; Colégio Pedro II; Escrita da História.
\end{abstract}

\section{Border and territorial integration in writing history "teaching" of Nineteenth century}

ABSTRACT: During the Regency period, in 1838, come into operation two institutions that aimed to create and legitimize historical writings to forge a nation to the newly emancipated Brazilian state: the Brazilian Historical and Geographical Institute (IHGB) and the first college in that history make school discipline. To achieve the objectives of nation building, territorial integration and delimitation of its frontiers became fundamental. The objective is, in this text, analyze the IHGB and the College Pedro II, while entities linked to the imperial state, organizers of a national construction project in which the ratification of its borders was necessary, seeking discursive legitimation, based on holdings of territory in prior centuries, in which the design of the territory, historical result of the Portuguese expansionist policy, was in something of a tradition.

KEYWORDS: Border; Territory; IHGB; Pedro II School; History writing.

\section{Frontera e integración territorial en la escritura de la história "didática" del siglo XIX.}

RESUMEN: Durante el período de regencia, en 1838, empezaban su funcionamiento dos instituciones cuyo objetivo era crear y legitimar las escrituras históricas para forjar una nación para el recién emancipado Estado brasileño: el Instituto Histórico y Geográfico Brasileño (IHGB) y el primer Colegio en que la Historia se convertiría en una asignatura escolar. Para alcanzar estos objetivos de consolidación de la nación, la integración territorial y la delimitación de sus fronteras se tornaban fundamentales. El objetivo de este texto es el análisis del IHGB y del Colegio Pedro II, mientras entidades involucradas al Estado imperial, organizadoras de un proyecto de construcción nacional en el cual había la necesitad de la ratificación de sus fronteras, buscando por discursos de legitimidad, fundamentadas en las explotaciones del territorio realizadas en siglos anteriores, las cuales el diseño del territorio, resultado histórico de la política de expansión lusitana, se constituyó en una especie de tradición.

PALABRAS CLAVE: Frontera; Territorio; IHGB; Colegio Pedro II; Escritura de la Historia.

\footnotetext{
*Doutorando em História pela UFMT. Docente do Departamento de História da UNEMAT/Cáceres. Bolsista Capes/Fapemat. Email: lcesar@unemat.br.

*** Doutor em História pela UNICAMP. Docente do Departamento de História e do Programa de Pós-graduação em História da UFMT/Cuiabá. E-mail: rrrenilson@yahoo.com.
} 


\section{História (ensinada) e a construção da nação}

Currículos, livros didáticos de História, disciplina escolar, territórios, identidades, migrações e fronteiras. Demandas do tempo presente que encontram ressonância em séculos passados. Certamente os sentidos podem ter sofrido algumas alterações, pois todos esses conceitos são construídos temporal e espacialmente, por determinados grupos que obtiveram relativa hegemonia.

A história ensinada, apesar de pouca visibilidade curricular nos dias atuais, continua sendo importante, a exemplo de outras disciplinas afins, pois pode contribuir decisivamente para a formação crítica do ser humano, bem como desenvolver uma consciência plena de cidadania e trabalhar valores tão deturpados ou esquecidos nos dias atuais, principalmente no cenário político mundial. As aulas de História podem oferecer instrumentos de análise interessantes às demandas atuais, que normalmente são consequências de ações passadas e que devem ser tratadas de forma diacrônica. Se o Oitocentos serviu para legitimar o Estado nacional, por meio de narrativas históricas que impunham uma identidade e cultura únicas e homogêneas, hoje elas podem contribuir para o estudo das diversas identidades e culturas, bem como auxiliar uma compreensão ampla das mesmas, sem que promova silenciamentos de umas em detrimento de outras.

De acordo com Ariclê Vechia ${ }^{1}$, o sistema escolar na América portuguesa ficou a cargo dos jesuítas por mais de duzentos anos. Consistia basicamente em preparar os jovens filhos das elites para seguirem os estudos em Coimbra ou nas universidades francesas. Tais práticas permaneceram até 1759 , ano do decreto do marquês de Pombal que determinava a expulsão da Ordem de Portugal e de suas colônias. Em 1772 a Coroa portuguesa propôs um projeto que constituía o estabelecimento de aulas régias, ou seja, ensino de determinadas disciplinas autônomas e isoladas, ensinadas sem um plano de estudo estruturado ${ }^{2}$. É importante destacar que o perfil desse conjunto de disciplinas era clássico humanista, que gradativamente iriam disputar espaço com as disciplinas modernas, de caráter mais pragmático, bem como o ensino de línguas vivas como o inglês e francês.

A vinda da família real, em 1808, fomentou a criação de diversas instituições, dentre elas, liceus em diversas províncias, bem como escolas particulares e faculdades de Medicina e de Direito. Para Emília Viotti da Costa, dentre as medidas adotadas por D. João VI, as mais nefastas aos portugueses que ficaram na metrópole foram a extinção do monopólio comercial e a abertura dos portos $^{3}$. A insatisfação dos comerciantes culminou no levante da cidade do 
Porto, cujas exigências imediatas se pautavam no retorno do rei e a restituição do pacto colonial, o que colocaria frente a frente os interesses dos comerciantes lusitanos em Portugal e no Brasil. Dentre as possibilidades estavam a de restabelecer o regime anterior à vinda da Corte para o Rio de Janeiro, ou mesmo o estabelecimento de uma Monarquia dual com sedes simultâneas no Brasil e Portugal. Ganhou espaço a possibilidade da proclamação da independência, procurando preservar a autonomia administrativa e comercial alcançada. A manutenção do príncipe D. Pedro propiciou a realização de tal ato sem alteração da ordem social. Adotar a solução monárquica de governo significaria uma "revolução" de cima para baixo, dispensando mobilizações populares, garantindo assim a manutenção da unidade e uma personagem simbólica que poderia ajudar a manter a ordem.

Logo após a Abdicação ocorreu a reformulação do Código de Processo Criminal e a instituição do Ato Adicional de 1834. Buscava-se uma maior autonomia para as províncias, mas com a permanência da ordem e da integridade nacional. O Código, aprovado em 29 de novembro de 1832, tornava-se a personificação de um dos principais instrumentos da descentralização, estabelecia que o poder judiciário fosse independente do administrativo, e que o promotor, o juiz municipal e o juiz de órfãos, até então nomeados pelo governo central, passassem a ser escolhidos a partir de uma lista tríplice proposta pela Câmara Municipal.

Motivado pelo Ato Adicional de 1834, que criou algumas medidas descentralizadoras, urgiu a necessidade de uma centralização política motivada principalmente pelo perigo de uma fragmentação territorial, motivada por diversos levantes regionais que contestavam os governos regenciais. Nesse contexto, denominado Regresso conservador, foram criadas duas das principais instituições que teriam como preocupação o ensino e a sistematização dos estudos históricos: O Colégio de Pedro II e o Instituto Histórico e Geográfico Brasileiro (IHGB). Este tendo a frente o grupo denominado facção áulica, liderado por Aureliano de Souza e Oliveira Coutinho (1800-1855) e aquele tendo como principal idealizador o ministro Bernardo Pereira de Vasconcellos (1795-1850), que à época acumulava as pastas do Império e da Justiça.

Assim, uma entidade destinada a coleta e sistematização da memória e a outra encarregada de se tornar o modelo de ensino da e para a jovem nação monárquica brasileira seriam alguns dos principais alicerces de sua consolidação e legitimação. No Colégio, o conjunto de saberes dispersos em aulas avulsas, nos moldes das aulas régias, se configuraria distribuído em disciplinas ao longo de oito séries. Para Thais Nívia de Lima e Fonseca, as 
disciplinas escolares surgiram do interesse de grupos e instituições, sobretudo Igreja e Estado ${ }^{4}$.

A História, enquanto um singular coletivo, nos termos de Reinhart Koselleck, surgiu no contexto da consolidação dos Estados nacionais a partir da segunda metade do século XVIII, intensificando-se ao longo do século $\mathrm{XIX}^{5}$. O seu ensino sistemático, propiciado pelo processo de disciplinarização em instituições que a ofereciam de forma seriada constituiu-se em um importante veículo de manutenção e legitimação do poder estatal. Dessa forma, institutos históricos e instituições de ensino, dentre outras agremiações fundadas no período, seriam as responsáveis pela elaboração intelectual que subsidiaria a implantação de projetos de construção nacional, nos quais a delimitação do território e o estabelecimento de suas fronteiras seriam fundamentais.

O IHGB, que iniciou suas atividades em 21 de outubro de 1838, trataria de prescrever formas para a escrita de uma narrativa nacional por meio de sua Revista, em circulação ininterrupta desde 1839, e outras publicações. Ao passo que o Imperial Colégio de Pedro II, fundado em 1837, seria o encarregado de disseminá-la para os filhos da elite intelectual do Império, pois foi concebido para ser modelo a ser seguido pelas demais instituições de ensino espalhadas pelo território brasileiro.

\section{O Instituto Histórico autodenominado brasileiro e o desenho da fronteira oeste}

Ao analisar o periódico do IHGB, em circulação ininterrupta desde 1839, nota-se uma preocupação, por parte do Instituto, acerca da necessidade de se esboçar um projeto de nação para a monarquia brasileira, buscando a delimitação de suas fronteiras e visando integrar os territórios, principalmente os distantes da Corte litorânea. O esforço se justificava a fim de fundamentar um projeto de identidade nacional, indo ao encontro dos anseios do Estado que necessitava justificar sua condição política singular perante as Repúblicas sulamericanas, ao mesmo tempo teriam de inserir o país no quadro das nações civilizadas. Nesse sentido, buscava-se coletar documentos nas províncias e no exterior para se constituir uma memória nacional e eleger os grandes vultos da pátria para protagonizarem-na. Esses documentos teriam relevância à medida que trouxessem informações estatísticas, geográficas, históricas ou etnográficas sobre os territórios do interior, principalmente os localizados nas regiões de fronteira.

Logo na quinta reunião, em 16 de fevereiro de 1839, por exemplo, o Visconde de São Leopoldo, presidente do Instituto, leu um trabalho seu intitulado: quais são os limites 
naturais, pactuados e necessários do Império do Brasil? Julgada de suma importância, a sua imediata publicação foi aprovada pelos associados presentes ${ }^{6}$.

Ao elaborar um estudo sobre o IHGB, Manoel Luís Salgado Guimarães ${ }^{7}$ analisou a instituição articulada com o projeto de construção da ideia de nação e civilização no Brasil Imperial. Em relação à Revista, o autor afirmou que ela se constituía em espaço privilegiado para se rastrear o projeto ambicioso do Instituto Histórico, pois além de registrar as suas atividades por meio de seus relatórios, divulgar cerimônias e atos comemorativos diversos, suas páginas se abriram à publicação de fontes primárias como forma de preservar as informações nelas contidas - aliás, parte representativa de seu conteúdo nos primeiros tempos; de artigos, biografias e resenhas de obras.

Além disso, o IHGB, tendo como protetor o imperador Pedro II, premiava os melhores trabalhos sobre a geografia e a estatística das províncias, acerca da melhor maneira de se catequizar os indígenas para utilização como mão de obra ou sobre "como se deveria escrever a história do Brasil", esta última constituindo-se enquanto título de uma monografia escrita pelo botânico naturalista e sócio do Instituto Karl F. Ph. von Martius (1794-1868). Premiado em 1847, tornou-se uma espécie de guia que inspiraria quem se lançasse a missão de escrever uma História Geral do Brasil - tarefa executada em 1854 por Francisco Adolpho de Varnhagen, (1816-1876), diplomata e sócio correspondente do Instituto ${ }^{8}$.

A porção oeste do território brasileiro, em especial a Província do Mato Grosso, assim como outras regiões de fronteira, era uma constante preocupação por parte do Instituto, principalmente nos assuntos relacionados à delimitação de seus limites com os países vizinhos, fazendo-se muito mais presente na Revista no período que antecedeu à Guerra da Tríplice Aliança com o Paraguai (1864-70), surgindo ora como capitania, condição de 1748 até 1822; ora como província (1822-89), evidenciando preocupações por parte do Instituto também com os acontecimentos do tempo presente, principalmente eventos envolvendo questões de limites, descrições geográficas e de rios e a questão da livre navegação com a República do Paraguai. Após o término do conflito até o final do período imperial, em 1889, Mato Grosso praticamente desaparece das páginas da Revista, cedendo lugar para outras regiões fronteiriças como Rio Grande do Sul, em que já tinham resolvido seus conflitos políticos 9 .

As viagens de exploração ao interior do território mereceram também destaque por parte da Revista no período. Era preciso conhecer o interior, publicando na Revista, diários e descrições pormenorizadas sobre essas remotas regiões. Partindo das demarcações de limites 
efetuados no território durante o século XVIII se tentava legitimar divergências fronteiriças e mensurar o território no XIX.

Essa preferência temática converge para a preocupação maior do Instituto Histórico: o perigo de uma fragmentação territorial, a exemplo do que aconteceu com as ex-colônias espanholas; a manutenção dos limites demarcados a partir do Tratado de Madri, em 1750, seria fundamental para esse projeto de nação. Limites estes que não ficaram totalmente claros, principalmente os com o Paraguai, assim como a livre navegação pelo rio homônimo. $\mathrm{O}$ Brasil buscaria legitimar suas fronteiras oitocentistas por meio dos documentos coletados nos séculos anteriores. A escrita da História fundamentando a produção da nacionalidade, encontraria e nas páginas da Revista do IHGB um importante veículo para divulgação e circulação dessas ideias, tanto no Brasil quanto no exterior.

Em termos conceituais, analisar a fronteira e o território segundo suas alterações no decorrer do tempo, torna-se um exercício historiográfico interessante para se perceber de que forma essa região de fronteira era apreendida pelo centro do poder.

Conceitos requerem atenção e rigor. Os de fronteira e território, assim como tantos outros, devem ser abordados enquanto uma construção efetivada por diferentes sujeitos em determinado lugar social e em determinada época. Não se pode ignorar as dimensões temporais, espaciais e motivacionais inerentes ao surgimento do termo.

Território (espaço humanizado) é uma necessidade inerente a processos de formação do Estado, ou seja, suas características inicialmente são eminentemente políticas e geográficas. Assim, território está intimamente ligado a um poder centralizado, o qual precisa desse espaço sujeito à interferência humana para se estabelecer, expandir, se for o caso, ou proteger-se de outros Estados em expansão. Essa concepção de território se fez presente nas primeiras obras didáticas, bem como ainda se mantém alguns resquícios nos livros didáticos de História atuais.

O conceito deve ser analisado enquanto uma produção, que responda aos anseios do grupo que o formulou, assim como a sociedade e culturas envolvidas, tempos e espaços. Assim, fronteira é necessariamente um conceito relacional ${ }^{10}$. Para Castrillon-Mendes, o termo é complexo e polissêmico; tanto que discursivamente possui vários sentidos, quais sejam: "linha, um traçado no mapa; respeito; imaginário, força, guarnição militar; movimento, manutenção, penetração, povoação; ou mesmo como vassalagem, cumprimento de ordens, obediência"11. 
O sentido desse conceito utilizado neste texto corresponde a um dos sentidos adotados por Lylia Galetti:

(...) a fronteira no seu sentido de limite geopolítico entre Estados, separando as possessões territoriais de Espanha e Portugal, distinguindo soberanias, despertando identidades territoriais ${ }^{12}$.

Outros sentidos apontados pela autora em sua obra são: a fronteira como limite entre o sertão e a região colonial, espaço este já conhecido pelo colonizador e também a fronteira como um espaço novo e promissor. Adotou-se para a elaboração deste texto o sentido do termo geopolítica, conforme a concepção apontada por Otávio Canavarros: "uma política dos Estados europeus do século XVIII visando a obtenção de vantagens territoriais ou econômicas para os seus reinos, em detrimento de seus adversários"13.

É sabido que a fronteira entre os territórios colonizados por Portugal e Espanha, a partir do Século XVI, nem sempre se estabeleceu da mesma forma. De 1580 até 1640, por exemplo, as duas Coroas se uniram e essa fronteira se tornou mais fluida, fato conhecido como União Ibérica, em que o rei da Espanha passou a ser rei de Portugal também. Esse acontecimento inusitado contribuiu para que se consolidasse o avanço dos portugueses sobre a linha demarcatória de Tordesilhas de 1494 bem como a invasão da até então América portuguesa pelos holandeses, inimigos da Espanha.

Durante o século XVIII, diante desse alargamento fronteiriço, houve a necessidade de se estabelecer novos tratados limítrofes entre os países ibéricos. Já no século seguinte, com as emancipações políticas das colônias americanas, a fim de integrar seus territórios, deveria se estabelecer em definitivo a raia fronteiriça entre a agora Monarquia brasileira e as repúblicas vizinhas.

A questão dos tratados de delimitação de fronteiras insere-se na política expansionista lusitana, na qual a criação da Capitania de Mato Grosso e a fundação de Vila Bela da Santíssima Trindade, na porção noroeste, são os melhores exemplos das intenções da Coroa portuguesa para com essa região de fronteira. As cláusulas estabelecidas no Tratado, assinado em Madri, foram as primeiras a se efetivarem na prática, por meio das partidas demarcatórias de limites, que em 1754 plantaram um marco próximo à foz do rio Jauru. De acordo com Otávio Canavarros ${ }^{14}$, o Marco do Jauru foi um símbolo da vitória dessa política que transformou as linhas dos rios Paraguai-Guaporé nas primeiras fronteiras definitivas do Brasil. 
Tratados de limites anteriores, como por exemplo, a linha de Tordesilhas (uma fronteira imaginária), estabelecida no papel, em junho de 1494, sujeitava-se às mais variadas leituras pelos exploradores. Essa linha poderia alargar-se ou encurtar-se conforme interesses de quem a demarcava ${ }^{15}$. As melhores fronteiras, na concepção portuguesa, seriam as balizas naturais e elas poderiam muito bem substituir as geométricas.

A idealização do território enquanto uma vasta ilha continente, serviu como um programa geopolítico para as fronteiras com o propósito de se colonizar o Brasil, ordenando e orientando as estratégias desenvolvidas no Prata e no Amazonas. Essa concepção da IlhaBrasil, de acordo com Jaime Cortesão, é essencialmente política e geográfica, encontrando sua mais alta expressão na cartografia. Foi uma reação direta ao Tratado de Tordesilhas ${ }^{16}$.

Dessa forma, fixou-se o conceito de um Brasil, pelos exploradores lusitanos, enquanto uma vasta ilha amazônico-platina, dividida em várias outras ilhas e por outros rios, nascidos a partir de uma imensa lagoa, conhecida pelos exploradores espanhóis até as últimas décadas do Setecentos, por "Laguna del Xarayes", onde o curso do Amazonas se fundiria com o do Madeira, para ir ao encontro do Paraguai ${ }^{17}$.

Estabeleceu-se dessa forma, o futuro território nacional como um todo coerente, estruturado pela própria natureza, ocupado pela marcha da colonização e legitimado pela letra do Tratado entre as Coroas portuguesa e espanhola ${ }^{18}$. A linha demarcatória artificial de Tordesilhas era burlada pelos lusitanos em prol da identificação com as fronteiras desenhadas pela natureza, nas quais as águas seriam as melhores raias. A ilha Brasil invocava uma verdade prévia, anterior à história, uma terra preexistente, de um lugar de contornos definidos, de uma entidade indivisível. O Brasil erguia-se como uma realidade geográfica anterior à colonização.

Os intelectuais do IHGB, da mesma forma que a Coroa portuguesa no século anterior, observavam essa faixa fronteiriça como um espaço que separava o interior do território sob o domínio de diferentes sociedades indígenas e que servia, ou deveria servir como uma barreira para impedir um possível avanço agora das Repúblicas, ou anteriormente dos espanhóis. Dessa forma, o significado geopolítico da noção de fronteira seria o de uma zona limite entre soberanias distintas, representadas pelas Coroas ibéricas do século XVIII ou pelo Império brasileiro e as Repúblicas no XIX.

Cabe destacar que o significado dessa fronteira oeste seria apreendido segundo uma linha "estática", um limite entre a Monarquia, herdeira das luzes europeias e as repúblicas, tidas pelos monarquistas brasileiros como a região da barbárie. 
Sob esse prisma, as fronteiras nacionais eram uma das principais preocupações do poder imperial. Integrar as províncias seria fundamental para a implantação e a consolidação do Estado e do ideal de nação civilizada.

Essa unidade territorial, um "legado" do período colonial, seria legitimada por meio da Revista do IHGB na medida em que apareciam publicadas os diários de demarcações, descrições de rios, notícias de grupos indígenas, descrições das Capitanias, relatórios, dentre outros assuntos. Além do já citado trabalho do visconde de São Leopoldo acerca da fronteira sul, foram veiculados outros textos sobre o mapeamento do território na fronteira oeste, tais como: Serra (1840, 1844 e 1857); Leverger (1865) e Florence (1875 e 1876). Nessas descrições do território havia a preocupação - por parte dos viajantes exploradores -, acerca da extensão de mais de quatrocentas léguas, de uma Capitania que pouco rendia aos cofres imperiais, que não estaria preparada para uma guerra e que era limítrofe aos povoados estabelecidos pelos espanhóis ${ }^{19}$. O investimento em recuperar documentos do passado colonial acerca dessa fronteira foi de tal vulto que, durante o período monárquico, a Capitania de Mato Grosso foi a que mais obteve publicações no periódico do IHGB, ficando atrás apenas do Rio de Janeiro.

Essas preocupações com a integridade territorial e uma demarcação definitiva das fronteiras serão também abordadas didaticamente nos manuais de História do Brasil utilizados no Colégio criado para ser modelo para outros congêneres no país, como se verá a seguir.

\section{O Imperial Colégio e a História do Brasil em Lições: Os manuais dos médicos historiadores}

O Colégio Pedro II foi criado em 1837, com o objetivo de servir de modelo para as outras instituições de ensino secundário e visava combater as aulas avulsas e os exames preparatórios, práticas comuns à época. Esses exames promoviam o acesso aos cursos superiores sem a necessidade de comprovar estudos secundários completos. Dessa forma, a criação dessa instituição pode ser vista como uma primeira tentativa de centralização educacional e o início de um longo processo de consolidação do estudo secundário seriado. Essa medida estabelecia homogeneização do ensino para todo o país, por meio da adoção dos currículos e livros didáticos equiparados ao Colégio.

Para subsidiar os professores da instituição, seriam necessários a criação e desenvolvimento daquilo que hoje conhecemos por livros didáticos. Nesse sentido, escritores 
se lançaram a tal empreitada, que com o passar dos anos passou a dar prestígio social e rentabilidade financeira para aqueles que tivessem suas obras adotadas nos estabelecimentos de ensino.

O militar Henrique Luís de Niemeyer Bellegarde (1802-1839) foi o primeiro a escrever uma obra de história utilizada como manual no Imperial Colégio, elaborado a partir da tradução do Résumé de l'histoire Du Brésil (1825), de Jean Ferdinand Denis (1798-1890).

De acordo com Circe Bittencourt, o Resumo de Bellegarde, depois de seu falecimento, teve outras edições com acréscimos e adaptações realizadas pelo seu irmão, o também militar Pedro de Alcântara Bellegarde (1807- 1864). Uma terceira edição saiu em 1845 e uma quinta e última em 1855, significando que o livro teve aceitação ao menos em escolas militares ${ }^{20}$. Esta obra, vale evidenciar, começou a circular por essas instituições, antes mesmo da fundação do Colégio Pedro II, ocorrida somente em 1837. Neste Colégio o Resumo foi adotado entre 1841 e 1856, uma vez que apesar de não aparecer nos programas, foi autorizado pelo ministro do Império Antonio Carlos de Andrada e Silva (1773-1845), de acordo com Escragnolle Doria ${ }^{21}$.

O segundo manual de História do Brasil utilizado no Colégio foi o do general José Inácio de Abreu e Lima (1794-1869). Abreu e Lima foi admitido em 1839, como membro honorário do IHGB, ao qual enviou, em setembro de 1843, o seu Compendio da História do Brazil, junto com uma carta ao primeiro secretário, o cônego Januário da Cunha Barbosa. Nela se gabava "da glória de ter dado o primeiro passo na carreira escabrosa de historiador" 22 . Porém, foi interditado pela instituição sob a acusação de plágio por parte de Francisco Adolfo de Varnhagen, que havia sido encarregado pelo secretário do IHGB de emitir juízo sobre o Compendio. O veto de Varnhagen e do IHGB não impediu a obra, inicialmente em dois volumes, fosse adotado no Colégio Pedro II a partir de $1856^{23}$.

Portanto, os dois primeiros manuais de História do Brasil adotados no primeiro Colégio seriado são exemplos que denotam a não interferência do IHGB, pelo menos no processo de elaboração: a obra de Bellegarde (1834) foi produzida antes mesmo da fundação do Instituto e a de Abreu e Lima (1843) a partir de outro lugar sócio-institucional ${ }^{24}$, já que nesse período o general dificilmente frequentava as reuniões do Instituto e já era um autor de prestígio na Província de Pernambuco. Da mesma forma, pode-se inferir que ambas as obras foram compostas, pelo menos em suas primeiras edições, como não destinadas a finalidades didáticas. Arlette Medeiros Gasparello classifica essas primeiras obras adotadas no Colégio Pedro II como "história patriótica", ou seja, uma primeira etapa da história didática ${ }^{25}$. 
A relativa estabilidade da Monarquia pós-1848, com o fim dos levantes nas províncias, além do ministério da conciliação, dois anos depois, propiciaram ao aparecimento de obras que foram pensadas e acolhidas enquanto modelos legitimadores de uma narrativa nacional sob o ponto de vista do Estado monárquico constitucional brasileiro; uma segunda etapa da produção didática, uma história oficial e imperial, nos termos de Gasparello. Para tanto, as diretrizes historiográficas já havia sido lançadas pelo naturalista Karl F. Ph. von Martius, em1844, ao vencer o concurso proposto pelo IHGB em 1840, sobre o melhor plano para se escrever a História do Brasil.

Em 1854 Francisco Adolfo de Varnhagen, reconhecido pela intensa pesquisa documental realizadas em arquivos no Brasil e no exterior, já havia escrito a sua História Geral, que se tornaria a obra que fundamentaria os manuais de história analisados a seguir, pois, refletia uma interpretação do passado fundamentada no papel civilizador do português e na herança e continuidade do Império lusitano. Assim, a obra do futuro Visconde de Porto Seguro serviria aos propósitos de Joaquim Manuel de Macedo e duas décadas depois a Luís de Queiros Mattoso Maia, ambos professores-autores do Colégio da Corte, que escreveram suas obras dirigidas aos seus alunos, ou seja, com finalidades didáticas, evidenciando suas propostas metodológicas. Os manuais analisados para este texto foram as edições das duas obras utilizadas no Colégio Pedro II, ou seja, aquelas destinadas especificamente aos alunos do ensino secundário da principal instituição de ensino do Império.

Ao elaborar as suas Lições de história do Brasil, manuais utilizados no Colégio Pedro II, a partir de 1861, no caso de Macedo, e após 1880, no caso de Mattoso Maia, se constituiriam, apesar de algumas críticas, numa constante presença não só no colégio modelo do Rio de Janeiro, mas também em muitos outros estabelecimentos de ensino a partir da segunda metade do século XIX, tendo um deles inclusive resistido a mudança de regime político em 1889 e convivido com outros manuais durante as primeiras décadas da República.

Joaquim Manuel de Macedo (1820-1882), catedrático de História Antiga e Geografia no Colégio Pedro II desde 1849, inaugurava uma nova etapa da produção didática com as suas Lições de Historia do Brazil para uso dos alunos do Imperial Colegio, publicadas em $1861^{26}$. Nesse período já havia migrado para a cátedra de História e Corografia do Brasil a partir de $1858^{27}$.

Além de lente do renomado colégio, por mais de trinta anos, Macedo foi secretário do IHGB entre 1852-56 e orador da mesma instituição durante três décadas, além de médico e renomado romancista e teatrólogo. Por isso torna-se uma personagem estrategicamente 
localizada na articulação entre dois lugares de produção discursiva: o "erudito" e o "didático". Além disso, é visível a presença do Visconde de Porto Seguro nas suas Lições, sobretudo, à ênfase em uma história política e administrativa e ao modelo de cronologia adotado - os chamados quadros de ferro - nas palavras de Capistrano de Abreu ${ }^{28}$.

Dessa forma, para Arlette Gasparello, a obra didática de Macedo contou com a força das representações sociais ligadas a três importantes instâncias, duas delas institucionais: o IHGB, que detinha o controle da produção historiográfica, e o Colégio Pedro II, referência maior na instrução secundária oficial. A terceira, a fonte básica para as suas Lições, a Historia geral do Brazil, escritas em 1854/1857, pelo Visconde de Porto Seguro, garantiria projeção e longevidade nas práticas escolares ${ }^{29}$.

Dois dos três manuais publicados por Macedo, a partir de suas aulas (1861 e 1863), foram endereçados aos alunos do Colégio Pedro II, conforme dito anteriormente. A publicação de 1865 foi elaborada especificamente para alunos da instrução primária. Esta última constituiu-se em uma espécie de resumo dos outros dois manuais; continha, quadros sinóticos mais sucintos e duas novidades: perguntas ao final de cada lição e as explicações, uma espécie de glossário. Este manual foi o que teve maior longevidade, várias reedições saíram dos prelos imperiais e também dos republicanos, a última delas até a segunda década do século passado, organizada por Rocha Pombo ${ }^{30}$.

Luís de Queirós Mattoso Maia publicou sua obra homônima duas décadas depois das Lições de Macedo, em 1880. A julgar pelos índices, parece que Maia fez uma cópia de Macedo. Porém, não foi bem assim, apesar dos dois autores trazerem o Visconde de Porto Seguro como principal referência, conforme indicação nas obras: Macedo nos seus prefácios e Maia nas suas notas de pé de página.

Nas últimas décadas da Monarquia, quando Mattoso Maia elaborou seu texto, o contexto era bem diferente dos anos mais otimistas em que Macedo confeccionou suas duas Lições. O final da guerra e suas consequências e a fundação do Partido Republicano, em 1870, além da questão abolicionista por resolver, evidenciavam uma fase de declínio do Império nos trópicos.

Da mesma forma que o professor romancista, Mattoso Maia exerceu a medicina antes de se tornar catedrático do Colégio, principalmente quando esteve de serviço como cirurgião-mor de brigada durante a guerra da Tríplice Aliança com o Paraguai, na qual teve a oportunidade de "affrontar sempre as balas do inimigo em plena acção de combate" 31 . 
Capistrano de Abreu o censurou por apoiar-se em Macedo, quando deveria ter se apoiado em Candido Mendes, apesar de Mattoso Maia referenciá-lo no seu texto, de acordo com Fernando Segismundo ${ }^{32}$ : "Macedo não é fonte, copia o visconde de Porto Seguro". Mattoso Maia viria a ser, junto com Silvio Romero e Moreira de Azevedo, examinador do historiador cearense quando este prestou concurso para ingressar no Colégio Pedro II em 1883. De acordo com Fernando Segismundo, Mattoso Maia tratou-o com polidez ${ }^{33}$.

É um autor sobre o qual não se encontram tantas informações a seu respeito. Como não foi sócio do IHGB não consta no dicionário biobibliográfico dessa instituição. Seu livro foi aprovado pela Diretoria Geral de Instrução Pública de Pernambuco, em 1881. No parecer consta a referida obra como "o melhor compendio de História do Brasil até hoje publicado e que deve ser approvado para uso dos estabelecimentos de instrucção secundaria da província"34. A sexta e última edição foi uma homenagem à sua memória com "sacrifício pecuniário pelo filho que estava convencido da plena aceitação que lhe prestará a mocidade brasileira" 35 . Prestou concurso no Colégio Pedro II em 1879, porém já era professor interino da instituição há três anos.

O manual utilizado neste texto é a quinta edição, publicada em 1898. A primeira edição é de 1880. Existe um exemplar no arquivo do IHGB, que apesar de não haver registro de data, trata-se da primeira edição. Em 1886 foi publicada a segunda edição, a terceira edição é de 1891, cujo exemplar pode ser manuseado no Laboratório de Ensino de Material Didático - LEMAD/FEUSP, a quarta saiu do prelo em 1895 e a sexta em 1908, na qual existe um exemplar na Biblioteca Central da UFMT. Nota-se que as Lições de Mattoso Maia transcenderam a mudança de regime político, figurando nos programas do Colégio até os anos finais do século XIX. O de Macedo não aparece nos programas de ensino após 1882, porém, isso não é garantia de que ele não tenha sido utilizado até o término do regime monárquico, ou até mesmo depois, pois, como visto anteriormente, o seu manual destinado às escolas primárias foi publicado até a década de 1920.

A seguir, analisaremos como as noções de territórios e fronteiras são veiculadas nas Lições de História do Brasil de Manoel de Macedo e Mattoso Maia.

\section{Território e fronteira enquanto tradições inventadas na História (didática) nacional}

Nos dois manuais analisados, a temática acerca do território e das fronteiras encontra-se respectivamente nos capítulos XV e XVI de Macedo e XXIV, XXV e XXVI de Mattoso Maia ${ }^{36}$. 
Porém, esse tema perpassa alguns outros capítulos, como por exemplo, os referentes à guerra contra os holandeses, período em que Portugal estava sob o domínio espanhol. Os autores professores elaboraram um panorama das diversas capitanias e a situação em que se encontravam. Macedo observou a criação da capitania do Cabo do Norte, em 1637, “com o intuito de cobrir o Amasonas contra os francezes de Cayena, (...) dando-lhe como limite septentrional o rio do Vicente Pinçon, só conserva hoje o nome indigena Oyapoc" ${ }^{\text {} 37}$. Logo à frente destaca uma expedição para explorar o rio Amazonas, a fim de garantir a navegação e a comunicação com o Peru, que garantiriam imensas vantagens à Espanha ${ }^{38}$. Mattoso Maia, por sua vez, afirmou: "não deixa de ter vantagem interrompermos a narrativa dos episodios bellicos para lançarmos um olhar sobre o estado em que se achavam as diversas capitanias do Brazil" 39 . Abordando a expedição de Pedro Teixeira para a exploração do rio Amazonas até o Peru, Maia registrou que este plantou um marco com as armas de Portugal, tomando posse do território, próximo à fronteira, em 16 de agosto de 1638.

Como se percebe, há ênfase nas evidências do passado colonial que justificariam e respaldariam as negociações acerca das fronteiras norte, sul e oeste. Fundamentado nas documentações seiscentistas, os diplomatas imperiais teriam subsídios para justificar que tradicionalmente essas porções territoriais pertenciam, desde tempos remotos, a Portugal e, por consequência, agora pertenceriam ao Brasil.

Os "indomitos e ousados" paulistas foram os próximos personagens abordados. Com a palavra, Macedo: "Fazendo uma revoltante colheita de mais de quinze mil capticvos, e provocando assim repetidas reclamações dos jesuitas. Indubitavelmente a causa dos paulistas offendia a razão e a justiça" ${ }^{40}$. Essas atitudes entrariam em rota de colisão com as "pretençoes exageradas dos padres da companhia (...) na questão da liberdade dos índios".Segundo o professor Macedo,

\footnotetext{
Os sertanejos de São Paulo não paravão em suas correrias, e no empenho de captivar gentios depois de chegar a Santa Catharina, de avançar até o Paraguay, (...) sem jamais desanimar pelas fadigas e perigos que tinhão de arrostar, esses avassalladores do deserto recebêrão ainda mais vigoroso impulso da ambição dos descobrimentos de minas e de pedras preciosas ${ }^{41}$.
}

$\mathrm{Na}$ questão dos constantes desentendimentos entre os colonos e os jesuítas, acerca da “interminável questão dos serviços dos índios”, Macedo lançou o seu veredicto sobre o governo português, "o principal culpado de tantas desgraças, que exasperava o povo com as suas provisões contraditorias" ${ }^{\prime 4}$. E prossegue: 
Era porem ainda preferivel que o governo de Lisboa se pronunciasse decididamente pelo captiveiro dos infelizes selvagens, do que deixar como deixou debatendo-se em conflictos e violencias os colonos e aquelles padres, em consequência das medidas sempre inconsistentes que tomava consecutivamente ${ }^{43}$.

Maia começou citando Macedo nos quatro pontos que este havia elencado para o desenvolvimento e progresso do Brasil no reinado de D. João V: discriminação das autoridades administrativas e judiciárias; descobrimento das minas auríferas pelos paulistas; povoação dos territórios de Minas Gerais, Goiás e Mato Grosso e a atenção para a colonização no sul do Brasil fazendo frente aos espanhóis ${ }^{44}$.

Adentrando ao tema dos paulistas, Maia se lembrou das ponderações de Capistrano de Abreu na sua tese de concurso: "as montanhas foram sempre a balisa, o pharol que tiveram aquelles homens emprehendedores, e os rios foram os caminhos que seguiram de preferência". E, na mesma página continua:

Até meiado do século XVII os paulistas lucravam mais com as expedições para escravisar índios e contra as reduções dos jesuítas do Paraguay e Uruguay do que nas suas tentativas de encontrar ouro; mas acontecia muitas vezes que esses bandeirantes achavam minas auríferas sem nellas pensar como succedeo com Pascoal Paes de Araujo e Antonio Pires de Campos ${ }^{45}$.

Em relação aos tratados de limites do Setecentos, Macedo chamou atenção para a falta de entendimento a respeito da linha de Tordesilhas entre Portugal e Espanha. A questão da Colônia do Sacramento, fundada por Portugal, havia sido tomada pela Espanha, no período da guerra da sucessão, após a morte de Carlos II. Pelo tratado de Utrecht, em 1715, a Colônia voltava novamente para os lusos. O tratado de Madri (1750) foi assinado com o propósito de resolver essas questões: a Espanha retomava a Colônia do Sacramento e cedia os Sete Povos das Missões a Portugal.

Os agentes históricos exaltados no capítulo Desenvolvimento e progresso do Brasil no reinado de D. João $V$, são os paulistas: “com o ardor infatigável e audácia irresistível os paulistas realisárão a conquista de vastos territórios, penetrando até Goyaz, Cuyabá e MattoGrosso, que começaram a povoar-se" ${ }^{\text {"46. }}$

$\mathrm{O}$ autor de A Moreninha registrou que esse cuidado por parte do governo com o sul do Brasil "não podia competir em ardor e actividade com os infatigáveis sertanejos de São Paulo, conquistadores do interior" ${ }^{\prime 4}$, devido às descobertas das "minas de Goyaz e do Cuyabá, 
além do paiz immenso conhecido pelo nome de Matto-Grosso, além da criação das villas Rica, Mariana e Sabará e de cinco novas capitanias e do bispado do Pará"48.

Mattoso Maia, da mesma forma, exaltou os feitos dos paulistas, elencando alguns nomes dos descobridores das minas auríferas e também destacou a descoberta do primeiro diamante no Brasil ${ }^{49}$.

Interessante o fato dos escritores, em pleno século XVI usarem o termo Brasil. Uma clara demonstração do uso do passado anterior à constituição do Estado para passar uma ideia de identidade nacional e reforçando o direito luso-brasileiro ao imenso território conquistado pelo avanço ao interior das terras pertencente a Espanha.

A personagem destacada pelos dois autores nas Lições (XVI de Macedo e XXVI de Maia) foi Sebastião José de Carvalho Mello, o Marquês de Pombal. Macedo já afirmou de início que se tratava de neto de uma "brasileira" e que foi o grande responsável pela tentativa de demarcação da fronteira pós-tratado de Madri. Tentativa porque os índios, instigados pelos jesuítas, "oppuzerão-lhes resistencia, afim de que elles não pudessem aproximar-se das fronteiras" $" 50$

A partir desse fato, Macedo apontou as medidas adotadas por Pombal e a reação por parte dos inacianos, que culminou com a assinatura da lei de 1759, que "abolio nos domínios portuguezes a companhia dos jesuitas. Em seguida justifica a atitude util e necessaria do ministro: luta desregrada com os interesses do Estado, abusando do seu poder sobre os rudes filhos do deserto". Macedo credita o fracasso da demarcação das divisas do sul e a posterior nulidade do tratado de 1750 "às dificuldades que havião embaraçado os demarcadores"51.

Sobre o "lamentável” tratado de 1777, o autor destaca que "o Brasil perdeu a colonia do Sacramento, as Missões do Uruguay, e não pouco território ao sul; rehavendo porém ao menos a ilha de Santa Catharina, deixou provada a incapacidade dos ministros do novo reinado" $^{, 52}$. $\mathrm{O}$ escritor deixa claro que se à frente do gabinete de Lisboa estivesse ainda $\mathrm{O}$ Marquês, esse tratado não seria celebrado, ou seriam outros os termos. Logo em seguida Macedo elenca as qualidades (e alguns defeitos) de Pombal, "o Richelieu portuguez”, e que teve a sorte de ter o "apoio inflexível do rei",53.

Mattoso Maia, que também observou o dito lamentável tratado de Santo Ildefonso, sobre o tema jesuítas exalta as qualidades de Pombal, assim como alguns defeitos. O pior deles foi a expulsão dos jesuítas: "não devia ser abolida e sim reformulada. Fundamentandose em Southey, um historiador insuspeito, tanto mais que era protestante", registrou a falta 
que essa supressão ocasionou, principalmente em relação aos índios que abandonaram as aldeias em que se tinham fixado e voltaram para a vida nômade e selvagem ${ }^{54}$.

Com relação às boas medidas adotadas pelo Marquês de Pombal, a reversão para o Estado das capitanias que ainda estavam em poder dos descendentes dos donatários. Citando o Visconde de Porto Seguro, elenca-as mostrando os valores pagos aos herdeiros.

Entre todos esses contras, o célebre ministro, concluiu o autor: "reunindo a altivez e implacabilidade de Richelieu, a sutileza e astucia de Mazarino e a obstinação e audacia de Alberone, fez com que Portugal parasse por algum tempo no caminho da decadência em que se ia despenhando",55.

\section{Criando tradições: territórios e fronteiras nas Lições de História do Brasil}

Os temas fronteira e território, cruciais para a consolidação do Estado monárquico brasileiro, figuram nas narrativas enquanto resultado natural de uma longa política acerca da construção do território e do desenho das fronteiras. Exaltando as incursões ao interior de portugueses e brasileiros desde os primórdios da colonização, sugerem que tradicionalmente teriam direito a um território desenhado pela natureza e as fronteiras já estariam definidas pelas aferições dos matemáticos e astrônomos desde os conflitos com holandeses no século XVII, e nos tratados de limites do Setecentos.

Nas narrativas ficou claro o sentimento de pertencimento à nação futura brasileira desde os primeiros séculos de colonização. Dessa forma, o manual escolar de História, baseado nas pesquisas de renomados historiadores, difundiria a ideia de que o desenho das fronteiras e o território brasileiro já estavam definidos pela mãe natureza e foi ratificado pela hábil atuação de ministros, reis e do corpo diplomático.

Os paulistas são destacados como os grandes responsáveis pelo alargamento das fronteiras, estimulados pela necessidade de capturar o negro da terra e descobrir minas de ouro e diamante. O conflito entre estes e os jesuítas foi inevitável devido a negligência do poder metropolitano. Tal fato serviu para legitimar a atitude do marquês de Pombal de expulsão da ordem jesuítica das colônias portuguesas.

Assim, ao professor de História, que algumas vezes era professor de Geografia e de Corografia, caso de Manoel de Macedo e Mattoso Maia, em alguns momentos no Colégio Pedro II, denota a concepção de Estado moderno, no qual tempo e espaço precisam estar integrados. Para Circe Bittencourt ${ }^{56}$, a legitimação pelo princípio do uti possidetis cedeu espaço para a noção de fronteiras naturais, que justificaria a incorporação de terras decorrente 
de guerras e os acordos políticos seriam fundamentados pelo conhecimento histórico em defesa do território nacional e de suas fronteiras.

Questões envolvendo território e o alargamento das fronteiras se apresentaram de forma marcante entre os autores estudados. Elas estarão presentes na narrativa, mesmo quando o assunto era outro, como por exemplo, as guerras pela posse da terra entre portugueses, holandeses, ingleses ou franceses. Os autores interromperam suas narrativas acerca da guerra holandesa, assim como as ameaças inglesa e francesa, para abordar as viagens de exploração ao interior do território, a fim de obedecer a ordem cronológica dos acontecimentos. Tal fato pode ser pensado em termos da relevância dos aspectos geográficos e mesmo corográficos, associados à História, a ponto de rivalizar e disputar espaço com a narrativa bélica, geralmente mais atrativa aos estudantes. Se esta representaria o mito fundacional da nação, aquelas fundamentariam a preocupação em se divulgar, nos manuais, toda a tradição de uma política voltada para a manutenção do território nacional.

Dessa maneira, o relato sobre a guerra intercalada com algumas expedições ao interior do território, encontrou ênfase nas narrativas dos dois médicos professores, cuja principal referência teórica fora o visconde de Porto Seguro. O renomado diplomata, um dos representantes historiográficos da elite Saquarema, priorizou uma narrativa comprometida com o desenho das fronteiras e a manutenção da unidade territorial, elevando as batalhas nos montes Guararapes, localizados em Pernambuco, à condição de mito de fundação nacional.

Os artífices do Império brasileiro, especialmente no final do período regencial e ao longo do Segundo Reinado, foram muito hábeis e eloquentes na construção de representações discursivas - escritas e imagéticas - que acabaram por forjar um tipo de memória oficial para a nação. Nessa tarefa de bem elaborar esta memória, por meio de uma costura de retalhos documentais, para dentro e para fora das divisas do país, destacou-se a atuação do IHGB, que, em associação com a Academia Imperial de Belas Artes, o Museu Nacional, o Arquivo Público do Império, as faculdades de direito e medicina e o Colégio Imperial Pedro II, daria à monarquia uma nova história, retratada em literatura épica, iconografia grandiosa, artefatos e monumentos, saberes institucionalizados que ministrariam uma pedagogia da nação, um corpo de leis e uma nacionalidade sadia desde os bancos escolares até as faculdades - locus de formação das elites.

No período, nesses locais, em especial no IHGB e Colégio Pedro II, enquanto a realeza era glorificada - a escravidão negra e a memória dos recentes conflitos regenciais 
ficariam relegadas a uma espécie de limbo - de maneira paralela e simétrica o passado era construído e celebrado, a partir da escolha de imagens e temas que destacavam a existência nos trópicos de uma pátria coroada de belezas, encantos e uma trajetória épica de feitos e conquistas. Forjava-se a representação de uma colônia que gradativamente aprendia a ser nação, ou seja, uma criança (Brasil) que, aos poucos, ia aprendendo a ser independente de sua mãe (Portugal) para seguir rumo a um futuro promissor nas mãos de uma monarquia. Esta fidelidade ao monarca seria uma característica muito forte dentro dessas instituições, mesmo após a proclamação da República em $1889 .{ }^{57}$

Nesse sentido, os historiadores Oitocentistas documentavam e narravam o passado, com os pés no seu presente - escrevendo uma história geral, que permitisse a consolidação do Império. Esses homens de letras teriam um papel relevante no desenho do território da nação - uma peça no quebra-cabeça de geopolítica do império no século XIX, articulada com o processo de centralização do Estado pela elite Saquarema.

\section{Notas}

${ }^{1}$ VECHIA, Ariclê. O ensino secundário no século XIX: instruindo as elites. In: STEPHANOU, Maria e BASTOS, Maria Helena Camara. Histórias e memórias da educação no Brasil. Petrópolis: Vozes, 2014, p. 7890.

${ }^{2}$ As disciplinas eram: ler e escrever, Latim, Grego, Retórica, e Filosofia. Ao final do século foram incluídas disciplinas de Matemática Elementar, Trigonometria e Desenho e Figura. Conferir: VECHIA, Ariclê. Op. Cit., p. 78-90.

${ }^{3}$ COSTA, Emília Viotti da. Da Monarquia à República: momentos decisivos. São Paulo: Ed. UNESP, 2007, p. 28.

${ }^{4}$ FONSECA, Thais Nívia de Lima e. História e ensino de História. Belo Horizonte: Autêntica, 2003, p. 15-16.

${ }^{5}$ Conferir: KOSELLECK, Reinhart. Futuro passado: Contribuição à semântica dos tempos modernos Rio de Janeiro: Contraponto/Ed. PUC-Rio, 2006.

${ }^{6}$ PINHEIRO, José Feliciano Fernandes. Quais são os limites naturais, pactuados e necessários do Império do Brasil? RIHGB. Rio de Janeiro, t. 1, 1839, p. 62.

${ }^{7}$ GUIMARÃES, Manoel Luiz Salgado. Nação e civilização nos trópicos: o Instituto Histórico e Geográfico Brasileiro e o projeto de uma história nacional. Estudos Históricos. Rio de Janeiro, n. 1, 1988, p. 5-27.

${ }^{8}$ GUIMARÃES, Manoel Luiz Salgado. Historiografia e nação no Brasil: 1838-1857. Rio de Janeiro: EdUERJ, 2011; RIBEIRO, Renilson Rosa. O Brasil inventado pelo Visconde de Porto Seguro: Francisco Adolfo de Varnhagen, o Instituto Histórico e Geográfico Brasileiro e a invenção do Brasil Colonial no Brasil Império (1838-1860). Cuiabá: Entrelinhas, 2015; MENDES, Luís César Castrillon. Publicar ou Arquivar? A Revista do IHGB e a escrita da História Geral do Brasil (1839-1889). Dissertação (Mestrado em História). Universidade Federal de Mato Grosso. Cuiabá, 2011.

${ }^{9}$ Essas regiões, embora sendo também de fronteira, inicialmente não apareceram na Revista, pois foram cenários de recentes conflitos, tais como a Revolução de 1817, em Pernambuco e a Farroupilha, no Rio Grande do Sul. Muitos dos seus participantes ainda estavam vivos e alguns deles eram sócios do IHGB.

${ }^{10}$ RODRIGUES, Candido M.; RIBEIRO, Renilson R.; ALMEIDA, Rodrigo D.; JOANONI NETO, Vitale. História: conceitos, metodologia e ensino. Cuiabá: EDUFMT; NEAD/UFMT; Universidade Aberta do Brasil, 2013, p. 88. 
${ }^{11}$ Cf. CASTRILLON-MENDES, Olga Maria. Taunay viajante: construção imagética de Mato Grosso. Cuiabá: EdUFMT, 2013.

${ }^{12}$ GALETTI, Lylia da Silva Guedes. Sertão, fronteira, Brasil: imagens de Mato Grosso no mapa da civilização. Cuiabá: Entrelinhas; EdUFMT, 2012, p. 80.

${ }^{13}$ CANAVARROS, Otávio. O Poder metropolitano em Cuiabá (1727-1752). Cuiabá: EdUFMT, 2004, p. 14.

${ }^{14}$ Idem, p. 339

${ }^{15}$ Para Renato Peixoto, o ato de se mapear um território é feito culturalmente: impressões e descrições são participantes de um mesmo processo de fabricação da identidade coletiva. Os mapas e as corografias, enquanto instrumentos dessa intervenção cultural são construídos a priori, no conjunto das representações de seus narradores e estão sujeitos, por conseguinte, a constante reelaborações da mesma identidade coletiva. PEIXOTO, Renato Amado. A Máscara da Medusa: A construção do espaço nacional brasileiro através das corografias e da cartografia no século XIX. Tese (Doutorado em História). Universidade Federal do Rio de Janeiro. Rio de Janeiro, 2005, p. 35.

${ }^{16}$ CORTESÃO, Jaime Zuzarte. Alexandre de Gusmão e o Tratado de Madri. t. II. Brasília: Fundação Alexandre de Gusmão; São Paulo: Imprensa Oficial do Estado de São Paulo, 2006, p. 135-136.

${ }^{17}$ COSTA, Maria de Fátima. A história de um país inexistente: Pantanal entre os séculos XVI e XVIII. São Paulo: Estação Liberdade; Kosmos, 1999.

${ }^{18}$ MAGNOLI, Demétrio. O corpo da Pátria: imaginação geográfica e política externa no Brasil (1808-1912). São Paulo: Editora UNESP, Moderna, 1997, p. 11.

${ }^{19}$ SERRA, Ricardo Franco de Almeida. Memoria ou informação dada ao Governo sobre a Capitania de MatoGrosso. RIHGB. Rio de Janeiro, t. 2, 1840, p. 46.

${ }^{20}$ Conferir: BITTENCOURT, Circe Maria Fernandes. Livro didático e saber escolar (1810-1910). Belo Horizonte: Autêntica, 2008.

${ }^{21}$ DORIA, Luis Gastão Escragnolle. Memoria Historica do Collegio de Pedro Segundo (1837-1937). Rio de Janeiro: Ministério da Educação e Saúde, 1937, p. 49.

${ }^{22}$ ABREU E LIMA, José Ignácio de. Carta ao primeiro secretário. Ata da sessão de 14/09/1843. RIHGB. Rio de Janeiro, t. 5, 1843, p. 395-397.

${ }^{23}$ VECHIA, Ariclê; LORENZ, Karl Michael. (Org.). Programa de ensino da escola secundária brasileira: 1850-1951. Curitiba: Ed. do Autor, 1998, p. 35.

${ }^{24} \mathrm{O}$ conceito foi desenvolvido por Michel de Certeau (2002).

${ }^{25}$ Conferir: GASPARELLO, Arlette Medeiros. Construtores de identidades: a pedagogia da nação nos livros didáticos da escola secundária brasileira. São Paulo: Iglu, 2004.

${ }^{26}$ Joaquim Manuel de Macedo publicou duas obras intituladas Lições de História do Brasil, que foram utilizadas no Colégio Pedro II: a de 1861, para alunos do $4^{\circ}$ ano e a de 1863 , para alunos do $7^{\circ}$ ano, que serão analisadas neste trabalho. Em 1865 ele publicou as Lições de História do Brasil para alunos da instrução primária, que teve maior longevidade do que os dois primeiros. Macedo publicou também em 1873, Lições de corografia do Brasil.

${ }^{27}$ MACEDO, Joaquim Manuel de. O Imperial Colégio de Pedro II. In: Um passeio pela cidade do Rio de Janeiro. Brasília: Edições do Senado Federal, 2005, p. 353.

${ }^{28}$ ABREU, João Capistrano de. Carta a Barão do Rio Branco, de 17 de abril de 1890. In: RODRIGUES, José Honório. Explicação. Capítulos de História colonial. Belo Horizonte: Itatiaia; São Paulo: Edusp, 1988, p. 13.

${ }^{29}$ GASPARELLO, Arlette Medeiros. Construtores de identidades: a pedagogia da nação nos livros didáticos da escola secundária brasileira. São Paulo: Iglu, 2004, p. 130.

30 Organizadas por Olavo Bilac e Rocha Pombo, respectivamente nos anos de 1907 e 1914. Conferir: ANDRADE, Vera Lúcia Cabana. Historiadores do IHGB catedráticos do Colégio Pedro II no Império. RIHGB. Rio de Janeiro, t. 168 (434), jan./mar. 2007, p. 226.

${ }^{31}$ MAIA, Luís de Queirós Mattoso. Lições de Historia do Brazil. 6 ed. Nictheroy: Typographia Amerino, 1908, s. p.

${ }^{32}$ SEGISMUNDO, Fernando. Excelências do Colégio Pedro II. Rio de Janeiro: Colégio Pedro II, 1993, p. 25-26.

${ }^{33}$ Idem, p. 26.

${ }^{34}$ MAIA, Luís de Queirós Mattoso. Op. Cit. 
${ }^{35}$ Idem.

${ }^{36}$ Macedo assim nomeou os dois capítulos: "Desenvolvimento e progresso do Brasil no reinado de D. João V" e "Reinado de D. José I. - Questões e lutas no sul do Brasil. Jesuitas e sua expulsão. - O marquez de Pombal". Mattoso Maia, Por sua vez assim intitulou os seus três capítulos: "Effeitos da guerra da successão de Hespanha no Brazil. - Lutas com os Hespanhoes ao sul. - Hostilidades dos Franceses commandados por Duclerc e Duguay Trouin no Rio de Janeiro. - Tratados de Utrecht e de Madrid, 1678-1750"; "Desenvolvimento e progresso do Brazil no reinado de D. João V" e, por último, "Reinado de D. José I. - Questões e lutas ao sul do Brazil. Jesuitas e sua expulsão. - O Marquez de Pombal, 1750-1777’.

${ }^{37}$ MACEDO, Joaquim Manuel de. Lições de história do Brasil para uso dos alumnos do Imperial Collegio de D. Pedro II. Rio de Janeiro: D. J. G. Brandão, t. 2, 1863, p. 99.

${ }^{38}$ Idem, p. 100-101.

${ }^{39}$ Idem, p. 139.

${ }^{40}$ Idem, p. 103 e 104.

${ }^{41}$ Idem, p. 151.

${ }^{42}$ Idem, 1863, p. 154.

${ }^{43}$ Idem, p. 162.

${ }^{44}$ MAIA, Luís de Queirós Mattoso. Lições de Historia do Brazil. Proferidas no internato do Gymnasio Nacional. 5 ed. correcta e augmentada. Rio de Janeiro: Francisco Alves, 1898, p. 194.

${ }^{45}$ Idem, p. 195.

${ }^{46}$ MACEDO, Joaquim Manuel de. Op. Cit., p. 194.

${ }^{47}$ Idem, p. 196.

${ }^{48}$ Idem, p. 197-8.

${ }^{49}$ MAIA, Luís de Queirós Mattoso. Op. Cit., p. 199.

${ }^{50}$ MACEDO, Joaquim Manuel de. Op. Cit., p. 202-3.

${ }^{51}$ Idem, p. 205 e 206.

${ }^{52}$ Idem, p. 211.

${ }^{53}$ Idem, p. 212.

${ }^{54}$ MAIA, Luís de Queirós Mattoso. Op. Cit., p. 210.

${ }^{55}$ Idem, p. 215.

${ }^{56}$ BITTENCOURT, Circe Maria Fernandes. Livro didático e saber escolar (1810-1910). Belo Horizonte: Autêntica, 2008, p. 140.

${ }^{57}$ Cf. SCHWARCZ, Lilia M. A natureza como paisagem: imagem e representação no Segundo Reinado. Revista USP. São Paulo, n. 58, jun./ago. 2003, p. 06-29.

\section{Fontes}

ABREU E LIMA, José Ignácio de. Compendio da Historia do Brasil desde a mais remota antiguidade até os nossos dias. Rio de Janeiro: Eduardo e Henrique Laemmert, 1843.

BELLEGARDE, Henrique Luiz de Niemeyer. Resumo da historia do Brasil. Rio de Janeiro: Tip. Gueffier, 1834.

Carta ao primeiro secretário. Ata da sessão de 14/09/1843. RIHGB. Rio de Janeiro, t. 5, 1843, p. 395-397.

FLORENCE, Hércules. Esboço da viagem feita pelo sr. Langsdorff no interior do Brasil. RIHGB. Rio de Janeiro, t. 38, 1875, p. 355-366; t. 39, 1876, p. 157-182.

LEVERGER, Augusto João Manuel. Breve memória relativa a corografia da Província de Mato Grosso. RIHGB. Rio de Janeiro, t. 28, 1865, p. 129-155. 
MACEDO, Joaquim Manuel de. Lições de história do Brasil para uso dos alumnos do Imperial Collegio de D. Pedro II. Rio de Janeiro: B. L. Garnier, t. 1, 1861.

Lições de história do Brasil para uso dos alumnos do Imperial Collegio de D. Pedro II. Rio de Janeiro: D. J. G. Brandão, t. 2, 1863.

O Imperial Colégio de Pedro II. In: Um passeio pela cidade do Rio de Janeiro.

Brasília: Edições do Senado Federal, 2005, p. 288-370.

MAIA, Luís de Queirós Mattoso. Lições de História do Brasil. Proferidas no Internato do Imperial Colégio de Pedro II. Rio de Janeiro: Dias da Silva Júnior, Typografo Editor, 1880.

Lições de Historia do Brazil. Proferidas no internato do Gymnasio Nacional. 5 edição correcta e augmentada. Rio de Janeiro: Francisco Alves, 1898.

Lições de Historia do Brazil. 6 ed. Nictheroy: Typographia Amerino, 1908.

MARTIUS, Karl Friedrich Phillip. Como se deve escrever a história do Brasil. RIHGB. Rio de Janeiro, t. 6, 1844, p. 381-403.

PINHEIRO, José Feliciano Fernandes. Quais são os limites naturais, pactuados e necessários do Império do Brasil? RIHGB. Rio de Janeiro, t. 1, 1839, p. 62.

SERRA, Ricardo Franco de Almeida. Memoria ou informação dada ao Governo sobre a Capitania de Mato-Grosso. RIHGB. Rio de Janeiro, t. 2, 1840, p. 19-48.

Extrato da descrição geográfica da Província de Mato Grosso feita em 1797. RIHGB. Rio de Janeiro, t. 6, 1844, p. 156-196.

Diario do Rio da Madeira. Viagem que a expedição destinada á demarcação de limites fez no rio Negro até Villa-Bella, capital do governo de Matto-Grosso. RIHGB. Rio de Janeiro, 1857 , p. 348-395.

Appendice - Extracto do Diario da diligencia ao reconhecimento do rio Paraguay, desde o lugar do Marco, na boca do rio Jaurú. RIHGB. Rio de Janeiro, t. 25, 1862, p. 319-330. VARNHAGEN, Francisco Adolfo de. História Geral do Brazil. 1 ed. Madri, Imprensa da V. de Dominguez, 1854, t. I;1857, t. II.

\section{Referências Bibliográficas}

ABREU, João Capistrano de. Carta a Barão do Rio Branco, de 17 de abril de 1890. In: José Honório Rodrigues. Explicação. Capítulos de História colonial. Belo Horizonte: Itatiaia; São Paulo: Edusp, 1988.

ANDRADE, Vera Lúcia Cabana. Historiadores do IHGB catedráticos do Colégio Pedro II no Império. RIHGB. Rio de Janeiro 168(434), jan./mar. 2007.

ARAUJO, Valdei Lopes de. A experiência do tempo: conceitos e narrativas na formação nacional brasileira (1813-1845). São Paulo: Hucitec, 2008.

BITTENCOURT, Circe Maria Fernandes. Ensino de História: fundamentos e métodos. São Paulo: Contexto, 2004.

Livro didático e saber escolar (1810-1910). Belo Horizonte: Autêntica, 2008.

CANAVARROS, Otávio. O Poder metropolitano em Cuiabá (1727-1752). Cuiabá: EdUFMT, 2004. 
CASTRILLON-MENDES, Olga Maria. Taunay viajante: construção imagética de Mato Grosso. Cuiabá: EdUFMT, 2013.

CERTEAU, Michel de. Operação Historiográfica. In: A Escrita da História. Tradução de Maria de Lourdes Menezes. 2 ed. Rio de Janeiro: Forense Universitária, 2002, p. 65-106.

CORTESÃO, Jaime Zuzarte. Alexandre de Gusmão e o Tratado de Madri. t. II. Brasília: Fundação Alexandre de Gusmão; São Paulo: Imprensa Oficial do Estado de São Paulo, 2006. COSTA, Emília Viotti da. Da Monarquia à República: momentos decisivos. São Paulo: Ed. UNESP, 2007.

COSTA, Maria de Fátima. A história de um país inexistente: Pantanal entre os séculos XVI e XVIII. São Paulo: Estação Liberdade; Kosmos, 1999.

DENIS, Ferdinand. Résumé de l'histoire Du Brésil suivi Du Résumé de l'histoire de La Guyane. Paris: Lecointe et Durey libraires, 1825.

DORIA, Luis Gastão Escragnolle. Memoria Historica do Collegio de Pedro segundo (18371937). Rio de Janeiro: Ministério da Educação e Saúde, 1937.

FONSECA, Thais Nívia de Lima e. História e ensino de História. Belo Horizonte: Autêntica, 2003.

GALETTI, Lylia da Silva Guedes. Sertão, fronteira, Brasil: imagens de Mato Grosso no mapa da civilização. Cuiabá: Entrelinhas; EdUFMT, 2012.

GASPARELLO, Arlette Medeiros. Construtores de identidades: a pedagogia da nação nos livros didáticos da escola secundária brasileira. São Paulo: Iglu, 2004.

GUIMARÃES, Manoel Luiz Salgado. Nação e civilização nos trópicos: o Instituto Histórico e Geográfico Brasileiro e o projeto de uma história nacional. Estudos Históricos. Rio de Janeiro, n. 1, 1988, p. 5-27.

Historiografia e nação no Brasil: 1838-1857. Rio de Janeiro: EdUERJ, 2011.

KOSELLECK, Reinhart. Futuro passado. Contribuição à semântica dos tempos modernos. Tradução de Wilma Patricia Maas e Carlos Almeida Pereira. Rio de Janeiro: Contraponto/Ed. PUC-Rio, 2006.

MAGNOLI, Demétrio. O corpo da Pátria: imaginação geográfica e política externa no Brasil (1808-1912). São Paulo: Editora UNESP, Moderna, 1997.

MENDES, Luís César Castrillon. Publicar ou Arquivar? A Revista do IHGB e a escrita da História Geral do Brasil (1839-1889). Dissertação (Mestrado em História). Universidade Federal de Mato Grosso. Cuiabá, 2011.

PEIXOTO, Renato Amado. A Máscara da Medusa: A construção do espaço nacional brasileiro através das corografias e da cartografia no século XIX. Tese (Doutorado em História). Universidade Federal do Rio de Janeiro. Rio de Janeiro, 2005.

RIBEIRO, Renilson Rosa. O Brasil inventado pelo visconde de Porto Seguro: Francisco Adolfo de Varnhagen, o Instituto Histórico e Geográfico Brasileiro e a invenção do Brasil Colonial no Brasil Império (1838-1860). Cuiabá: Entrelinhas, 2015.

RODRIGUES, Candido M.; RIBEIRO, Renilson R.; ALMEIDA, Rodrigo D.; JOANONI NETO, Vitale. História: conceitos, metodologia e ensino. Cuiabá: EDUFMT; NEAD/UFMT; Universidade Aberta do Brasil, 2013. 
SCHWARCZ, Lilia M. A natureza como paisagem: imagem e representação no Segundo Reinado. Revista USP. São Paulo, n. 58, jun./ago. 2003, p. 06-29.

SEGISMUNDO, Fernando. Excelências do Colégio Pedro II. Rio de Janeiro: Colégio Pedro II, 1993.

VECHIA, Ariclê. O ensino secundário no século XIX: instruindo as elites. In: STEPHANOU, Maria e BASTOS, Maria Helena Camara. Histórias e memórias da educação no Brasil. Petrópolis: Vozes, 2014, p. 78-90.

VECHIA, Ariclê; LORENZ, Karl Michael. (Org.). Programa de ensino da escola secundária brasileira: 1850-1951. Curitiba: Ed. do Autor, 1998. 